\title{
Antimicrobial resistance patterns of phenotype Extended Spectrum Beta- Lactamase producing bacterial isolates in a referral hospital in northern Tanzania
}

DEBORA C. KAJEGUKA ${ }^{1 *}$, PETRO P. NAMBUNGA ${ }^{1}$, FRANK KABISSI ${ }^{1}$, BENJAMIN KAMUGISHA ${ }^{1}$, NANCY KASSAM ${ }^{1}$, BALTHAZAR NYOMBI ${ }^{2}$, CHACHA MATARO $^{2}$, VENANCE MARO ${ }^{2}$ and JAFFU O. CHILONGOLA ${ }^{1}$

${ }^{1}$ Faculty of Medicine, Kilimanjaro Christian Medical University College, Box 2240, Moshi, Tanzania

Department of Internal Medicine, Kilimanjaro Christian Medical Centre, Box 3010, Moshi, Tanzania

\begin{abstract}
Background: Production of Extended Spectrum Beta-Lactamase (ESBL) by bacteria is a chronic problem in a health care set up. In order to have adequate information for treatment of bacterial infections especially ESBL producing isolates, it is crucial to understand the trends in the antibiotic-resistance pattern, occurrence and their geographical spread. The objective of this study was to determine the antimicrobial resistance pattern among phenotype ESBL producing isolates in northern Tanzania.

Methods: From July 2013 to January 2014, urine, pus and blood samples were collected from patients suspected to have bacterial infections at Kilimanjaro Christian Medical Centre in Moshi, Tanzania. The isolates were identified based on standard laboratory procedures. Antimicrobial susceptibility tests were carried out using various antimicrobial discs as per the recommendations of Clinical Laboratory Standard Institute.

Results: A total of 330 specimens were collected. They consisted of 46 urine, 264 pus (from wound) and 20 blood samples. Among isolated bacteria, ESBL producers were $29.7 \%$ (98) and non-producers were $70.5 \%$ (232). Escherichia coli and Klebsiella pneumoniae were the most isolated bacteria and dominant ESBL producers. ESBL production was highly associated with moderate condition at discharge and longer periods of admission. More than $60 \%$ of the ESBL producing E. coli were resistant to ceftazidime, cefpodoxime, cefotaxime, amoxycilin, ciprofloxacin, and gentamycin. More than $80 \%$ of ESBL producing K. pneumonia and Proteus mirabilis were resistant to ceftazidime and cefotaxime. Fifty four percent of ESBL producing K. pneumonia were resistant to gentamycin. Conclusion: This study shows that ESLB phenotypes among Gram-negative bacteria are common among patients attending a tertiary hospital in northern in Tanzania. The findings suggest that clinical microbiology laboratories should take into account the diagnosis of ESBL producers in order to define the degree of the problem so as to establish a proper treatment protocol.
\end{abstract}

Keywords: Antimicrobial resistance, Extended spectrum beta lactamase, Tanzania

\section{Introduction}

Production of $\beta$-lactamase is the most commonly encountered mechanism of resistance of bacterial pathogens to $\beta$-lactam antibiotics. Extended-spectrum $\beta$-lactamases (ESBLs) are diverse, complex and rapidly evolving enzymes that are posing a major therapeutic challenge today in the treatment of patients (Rawat \& Nair, 2010). ESBL-producing gram-negative bacteria have posed a significant threat to patients due to their hydrolyzing activity against extended spectrum cephalosporin (Paterson et al., 2001; Paterson \& Bonomo, 2005) Resistance to third generation cephalosporin by possession and expression of ESBL enzymes among gramnegative bacilli is on a rise (Rawat \& Nair, 2010). ESBLs confer resistance not only to penicillin, aztreonam, and cephalosporin but could also be resistant to other antimicrobial classes including aminoglycosides, trimethoprim-sulfamethoxazole, and quinolones (Paterson et al., 2000; Paterson \& Bonomo, 2005).

\footnotetext{
*Correspondence Email: dkajeguka@gmail.com
} 
ESBLs are encoded by genes located on large plasmids, and these also carry genes for resistance to other antimicrobial agents (Paterson \& Bonomo, 2005). It has been documented that majority of ESBL producing bacteria are Klebsiella pneumoniae, K. oxytoca and Escherichia coli (Babini \& Livermore, 2000). The presence of ESBL producing bacteria significantly affects the course and outcome of an infection and poses a challenge to infection management worldwide (Tsering et al., 2009).

Patients may be affected with resistant bacteria or acquire resistance during/ prior antimicrobial exposure during treatment or in food residues (Food insight, 2012). Patients infected with ESBL-producing bacteria may have a higher mortality rate and may require longer hospital stays because they are generally sicker and have received more antibiotics than patients who are not infected with ESBL-producing bacteria (Ramphal \& Ambrose, 2006). It has been shown that infection caused by ESBL producing gram-negative bacteria complicate therapy and limit treatment options because such bacteria are resistant to a number of broadspectrum antibiotics (Paterson, 2000). The efficacy of antibiotic treatment is rapidly decreasing as a result of the continual spread of antibiotic resistance genes in pathogen populations. However, extent of ESBL-producing bacteria remains unclear in most parts of the world. This study aimed to provide baseline information on antibiotic resistance patterns mediated by ESBLs of bacteria isolated from urine, blood and pus samples in northern Tanzania. The objective of the study was to isolate ESBL producing bacterial isolates and to determine the clinical outcome of the patients infected with ESBL bacteria at a tertiary hospital in Tanzania.

\section{Materials and Methods}

\section{Study site}

Kilimanjaro Christian Medical Centre (KCMC) is a consultant referral hospital with 500-bed capacity. KCMC is located in Moshi town in northern Tanzania. It has a 500-bed capacity and the second largest consultant referral teaching hospital serving over 11 million people from northern and central regions of Tanzania (http://www.kcmc.ac.tz/).

\section{Specimen collection and identification of isolates}

Between July 2013 and January 2014, 330 consecutive and non-duplicate specimens (urine, blood and pus) were collected aseptically from all patients aged 1 to 80 years who attended outpatient and inpatient departments of the hospital. Specimens were transported to the Department of Microbiology laboratory and processed immediately. The specimens were cultured on to Mac-Conkey agar and blood agar plates. Culture plates were incubated aerobically at $37^{\circ} \mathrm{C}$ for $18-24$ hours and the colonies identified based on morphology. All patients with positive cultures were included in the study. Gram-negative bacilli isolated were characterized by performing gram's staining, motility and standard biochemical tests as described by Collee et al. (1996).

\section{Antimicrobial susceptibility testing}

Bacterial isolates were selected to determine their susceptibility patterns against selected antimicrobial agents, by the disc diffusion method of Kirby- Bauer as described by Clinical Laboratory Standards Institute (CLSI) (CLSI, 2011). The antimicrobial agents used were: gentamicin $(10 \mu \mathrm{g})$, Ciprofloxacin $(5 \mu \mathrm{g})$, amoxicillin $(10 \mu \mathrm{g})$, ceftriaxone $(30 \mu \mathrm{g})$, ceftazidime (30 $\mu \mathrm{g})$, cefotaxime $(30 \mu \mathrm{g})$ and cefpodoxime $(10 \mu \mathrm{g})$. Bacteria showing zone of inhibition of $\leq 25$ $\mathrm{mm}$ for ceftriaxone and ceftazidime were selected for confirmation test of ESBL, according to guidelines of CLSI (CLSI, 2011).

The potential ESBL producing bacteria were confirmed for ESBL production by phenotypic test. Briefly, a lawn culture of the isolated bacteria on Mueller Hinton agar (MHA) 
was made and ceftazidime $(30 \mu \mathrm{g})$ and the combination disc ceftazidime + clavulanic acid (30 $\mathrm{gg}$ $+10 \mu \mathrm{g}$ ) was placed with $25 \mathrm{~mm}$ apart. An increase of $\geq 5 \mathrm{~mm}$ in zone of inhibition for ceftazidime + clavulanic acid compared to ceftazidime alone was confirmed as ESBL producers, as per recommendations of CLSI (CLSI, 2011). ESBL producing Klebsiella pneumonia ATCC 700603 and non-ESBL producing E. coli ATCC 25922 were used as positive and negative control respectively.

\section{Clinical outcome determination}

Clinical outcome was evaluated as length of hospital stay (in days) after diagnosis of infection. Death was considered attributable to infection if occurred within two weeks from the diagnosis of infection, in the presence of clinical and laboratory evidence of active infection/ and or if it occurs during the admission period, and could not be strictly related to other fatal conditions. Death was considered to be unrelated to infection when it occurred more than two weeks after the diagnosis of infection or will be strictly related to other fatal conditions (BellíssimoRodrigues et al., 2006). A condition at discharge was scored as severe, moderate and mild. Patients were followed until hospital discharge.

\section{Data analysis}

Analysis of data was carried out using Statistical Package for Social Sciences (SPSS) version 20.0 (SPSS Inc., Chicago, USA).

\section{Ethical considerations}

During this study interviewers introduced themselves and explained the objectives and all procedures to all potential interviewees. A written consent form was obtained from adults or guardians of those individuals aged less than 18 years prior to inclusion. If the legal guardian was illiterate, signed consent was sought from another literate witness chosen by the guardian. This study received ethical approval from Kilimanjaro Christian Medical University College Research and Ethics Review Committee with Research Ethical clearance number 550.

\section{Results}

A total of 330 participants were recruited, more males were recruited than females. Adults ( $\geq 18$ years) were more recruited than children ( $<18$ years) (Table 1$)$. The specimens collected consisted of 46 urine, 264 pus (from wound) and 20 blood samples. Out of 330 bacteria isolates 214 were Gram-negative and 116 were Gram-positive bacteria. Escherichia coli and Klebsiella pneumonia were most isolated bacteria. Some $44.4 \%$ and $40.7 \%$ of E.coli and K. pneumonia were ESBL producers, respectively. We analyzed the association of ESBL producing bacteria and the clinical outcome of patients who were followed up. ESBL production was highly associated with moderate condition at discharge; $X^{2}=10.89$. $p=0.001$. ESBL production was also highly significantly associated with longer periods of admission $\left(X^{2}=19.83, p<0.001\right)$ (Table 1$)$.

ESBL producers were tested for their susceptibility to $3^{\text {rd }}$ generation cephalosporin. Generally, most of isolates were resistant to cephalosporin. More than $60 \%$ of the ESBL producing $E$. coli were resistant to ceftazidime, cefpodoxime and cefotaxime $(p<0.05)$. More than $90 \%$ and $80 \%$ of ESBL producing K. pneumonia and $P$. mirabilis were resistant to ceftazidime and cefotaxime, respectively $(p<0.05)$. Surprisingly all ESBL producing $P$. aureginosa were resistant to all $3^{\text {rd }}$ generation cephalosporin tested $(p<0.05)$ (Table 2$)$.

ESBL producers were also tested for their susceptibility to cephalosporin (amoxycilin, ciprofloxacin and gentamycin). More than $62 \%$ of ESBL producing E. coli were resistant to Amoxycilin, Ciprofloxacin and Gentamycin, $(p<0.05)$. Fifty four $(54.4) \%$ of ESBL producing $K$. pneumonia were resistant to Gentamycin, $(p<0.006)$. All $K$. oxytoka were resistant to 
Ciprofloxacin ( $p=0.002)$, and all P. aureginosa were susceptible to Gentamycin $(p=0.04)($ Table 3).

Table 1: Demographic characteristics and clinical outcome of ESBL producers and Non-ESBL producers in bacteraemic patients

\begin{tabular}{|c|c|c|c|c|c|}
\hline Characteristic & Variable & No. & $\begin{array}{l}\text { No. (\%) ESBL } \\
\text { producer }\end{array}$ & $\begin{array}{l}\text { No. (\%) Non- } \\
\text { ESBL producer }\end{array}$ & P-value \\
\hline All & & 330 & $98(29.7)$ & $232(70.5)$ & \\
\hline \multirow[t]{2}{*}{ Age (years) } & $<18$ & 70 & $26(37.1)$ & $44(62.9)$ & 0.1 \\
\hline & $\geq 18$ & 260 & $72(27.7)$ & $188(72.3)$ & \\
\hline \multirow[t]{2}{*}{ Sex } & Male & 212 & $66(31,1)$ & $146(68,9)$ & 0.4 \\
\hline & Female & 118 & $32(27.1)$ & $86(72.9)$ & \\
\hline \multirow[t]{2}{*}{ Department } & Inpatient & 280 & $10(20.0)$ & $40(80.0)$ & 0.1 \\
\hline & Outpatient & 50 & $88(31.4)$ & $192(68.8)$ & \\
\hline \multirow[t]{3}{*}{ Sample } & Urine & 46 & $10(27.7)$ & $26(78.3)$ & 0.4 \\
\hline & Pus & 264 & $82(31.1)$ & $182(68.9)$ & \\
\hline & Blood & 20 & $6(30.0)$ & $14(70.0)$ & \\
\hline \multirow[t]{5}{*}{ Ward/Clinic } & Medical & 20 & $8(40.0)$ & $12(60.0)$ & 0.7 \\
\hline & Surgical & 242 & $70(28.9)$ & $172(71.1)$ & \\
\hline & Urology & 58 & $18(31.0)$ & $40(69.0)$ & \\
\hline & OG & 8 & $2(25.0)$ & $6(75.0)$ & \\
\hline & Paediatric & 2 & $0(0.0)$ & $2(100.0)$ & \\
\hline \multirow[t]{6}{*}{ Bacteria isolate } & E. coli & 54 & $24(44.4)$ & $30(55.6)$ & 0.005 \\
\hline & K. pneumonia & 54 & $22(40.7)$ & $32(59.3)$ & \\
\hline & K. oxytoka & 10 & $2(20.0)$ & $8(80.0)$ & \\
\hline & P. aeruginosa & 32 & $8(25.0)$ & $24(75.0)$ & \\
\hline & P. mirabilis & 44 & $10(22.7)$ & $34(77.3)$ & \\
\hline & Other Proteus species & 20 & $8(40.0)$ & $12(60.0)$ & \\
\hline \multirow{2}{*}{ Condition at discharge } & Moderate & 16 & $12(75.0)$ & $4(25.0)$ & 0.001 \\
\hline & Mild & 28 & $6(21.4)$ & $22(78.6)$ & \\
\hline \multirow[t]{5}{*}{ Period of admission (days) } & 2 & & & & \\
\hline & $3-7$ & 34 & $10(29.4)$ & $24(70.6)$ & $<0.001$ \\
\hline & $8-14$ & 16 & $8(50.0)$ & $8(50.0)$ & \\
\hline & $15-21$ & 14 & $12(85.7)$ & $2(14 \cdot 3)$ & \\
\hline & $>21$ & 16 & $16(100.0)$ & $0(0.0)$ & \\
\hline
\end{tabular}

OG= Obstetrics \& Gynecology 
Table 2: Antibiotic resistance pattern of ESBL producing bacteria to $3^{\text {rd }}$ generation cephalosporin

\begin{tabular}{|c|c|c|c|c|c|c|c|c|c|c|}
\hline \multirow[t]{2}{*}{ Bacteria } & \multirow[t]{2}{*}{ No. } & \multicolumn{3}{|c|}{ Ceftazidime } & \multicolumn{3}{|c|}{ Cefpodoxime } & \multicolumn{3}{|c|}{ Cefotaxime } \\
\hline & & $S$ & $\mathbf{R}$ & p-value & $S$ & $\mathbf{R}$ & p-value & $S$ & $\mathbf{R}$ & p-value \\
\hline E. coli & 24 & $8(33.3 \%)$ & $16(66.7 \%)$ & $<0.001$ & $2(9.1 \%)$ & $20(90.9 \%)$ & 0.01 & $2(8.3 \%)$ & $22(91.7 \%)$ & $<0.001$ \\
\hline K. pneumoniae & 22 & $2(9.1 \%)$ & $20(90.9 \%)$ & $<0.001$ & $6(27.3 \%)$ & $16(72.7 \%)$ & 0.2 & $2(9.1 \%)$ & $20(90.9 \%)$ & $<0.001$ \\
\hline K.oxytoka & 2 & $0(0 \%)$ & $2(100 \%)$ & 0.002 & $2(100 \%)$ & $\mathrm{O}(0 \%)$ & 0.4 & $0(0 \%)$ & $2(100 \%)$ & 0.197 \\
\hline P.aeroginosa & 8 & $\mathrm{o}(0 \%)$ & $8(100 \%)$ & 0.001 & $0(0 \%)$ & $8(100 \%)$ & 0.007 & $0(0 \%)$ & $8(100 \%)$ & 0.02 \\
\hline P.mirabilis & 10 & $2(20 \%)$ & $8(80 \%)$ & $<0.001$ & $6(60 \%)$ & $4(40 \%)$ & 0.7 & $2(20 \%)$ & $8(80 \%)$ & 0.001 \\
\hline Other Proteus & 8 & $2(25 \%)$ & $6(75 \%)$ & 0.06 & $4(50 \%)$ & $4(50 \%)$ & 0.4 & $\mathrm{O}(0 \%)$ & $8(100 \%)$ & 0.003 \\
\hline
\end{tabular}

R=Resistant, S=Susceptible

Table 3: Antibiotic resistance pattern of ESBL producing bacteria to Non- $3^{\text {rd }}$ generation cephalosporin

\begin{tabular}{|c|c|c|c|c|c|c|c|c|c|c|}
\hline \multirow[t]{2}{*}{ Bacteria } & \multirow[t]{2}{*}{ No. } & \multicolumn{3}{|c|}{ Amoxycilin } & \multicolumn{3}{|c|}{ Ciprofloxacin } & \multicolumn{3}{|c|}{ Gentamycin } \\
\hline & & $S$ & $\mathbf{R}$ & $\begin{array}{l}\mathrm{p}- \\
\text { value }\end{array}$ & 5 & $\mathbf{R}$ & p-value & 5 & $\mathbf{R}$ & p-value \\
\hline E. coli & 24 & $2(8.3 \%)$ & $22(91.7 \%)$ & 0.005 & $9(37.5 \%)$ & $15(62.5 \%)$ & $<0.001$ & $6(25.0 \%)$ & $18(75.0 \%)$ & $<0.001$ \\
\hline K. pneumoniae & 22 & $4(18.2 \%)$ & $18(81.8 \%)$ & 0.05 & $14(63.6 \%)$ & $8(36.4 \%)$ & 0.1 & $10(45 \cdot 5 \%)$ & $12(54.5 \%)$ & 0.006 \\
\hline K.oxytoka & 2 & $0(0 \%)$ & $2(100 \%)$ & 0.1 & $0(0 \%)$ & $2(100 \%)$ & 0.002 & $\mathrm{o}(0 \%)$ & $2(100 \%)$ & 0.05 \\
\hline P.aeroginosa & 8 & $0(0 \%)$ & $8(100 \%)$ & 0.1 & $7(87.5 \%)$ & $1(12.5 \%)$ & 0.07 & $8(100 \%)$ & $0(0 \%)$ & 0.04 \\
\hline P.mirabilis & 10 & $4(40 \%)$ & $6(60 \%)$ & 0.4 & $8(80.0 \%)$ & $2(20 \%)$ & 0.2 & $4(40 \%)$ & $6(60 \%)$ & 0.5 \\
\hline Other Proteus & 8 & $0(0 \%)$ & $8(100 \%)$ & 0.06 & $6(75.0 \%)$ & $2(25.0 \%)$ & 0.06 & $4(50 \%)$ & $4(50 \%)$ & 0.1 \\
\hline
\end{tabular}

R=Resistant, S=Susceptible 


\section{Discussion}

In present study ESBL prevalence is high and comparable to findings from other studies in referral hospitals in Tanzania (Ndugulile et al., 2005; Kariuki et al., 2007; Mshana et al., 2011). In clinical settings in Tanzania, the prevalence of extended spectrum beta-lactamases (ESBL)producing bacteria ranges from 25\% to 50\% (Mshana et al.,2009, 2013a). Other studies in subSaharan Africa have shown similarly high levels (20-90\%) of antibiotic resistance for common isolates clones of ESBL producing Escherichia coli ST131 and Klebsiella pneumonia from humans and animals (Laxminarayan et al. 2013; Mshana et al., 2013a). ESBL producers were commonly found in E. coli and K. pneumonia with most of the bacteria isolated from pus samples. ESBL producing isolates were more common among the $\mathrm{E}$. coli as compared to the $\mathrm{K}$. pneumoniae isolates which is in agreement with the findings of a study by Umadevi et al. (2011). However, in a study by Mshana et al. (2009), K. pneumonia was reported as the most common ESBL producers.

Most ESBL producing isolates showed resistance to advance generation cephalosporins (cefotaxime, ceftazidime, and cefpodoxime). This could happen due to the incidental presence of various other mechanisms of resistance in a given bacterium. These findings are in agreement with previously published studies (Chander \& Shrestha, 2013). We have noted that ESBL producers were significantly resistant to ciprofloxacin and gentamicin, indicating cotransfer of aminoglycoside resistance on a resistance plasmid, thus posing clinical challenges. This phenomenon has been reported by other studies (Jocoby \& Sutton, 1991; Paterson, 2000; Spanu et al., 2002). The transfer of resistance from one bacteria species is possible and this is likely due to the fact that ESBLs are plasmid mediated. Plasmids carrying ESBLs are transferable from one bacteria to the next and between different bacterial species (Rupp \& Fey, 2003).

Patients infected with ESBL-producing bacteria may have a higher mortality rate and may require longer hospital stays because they are generally sicker and have received more antibiotics than patients who are not infected with ESBL-producing bacteria (Ramphal \& Ambrose, 2006). In this study we associated ESBL producers with longer hospital stay and condition at discharge, and we found significant association. Most patients infected with ESBL bacteria were hospitalized for more than three weeks, and this can cause high cost. Apart from high cost of care and treatment among hospitalized patients, continual exposure to antibiotics during hospitalization eventually can lead to development of resistance to bacteria. Moderate conditions during discharge were more pronounced among ESBL producers as compared to non-ESBL producers.

Most isolated ESBL producing bacteria were resistant to third generation cephasporins. Antimicrobial resistance has become a public health problem in Sub-Saharan Africa (Mshana et al., 2013b). Our data indicate high proportion of ESBL resistant isolates suggesting cepharosporins use should be limited in order to control the increasing treatment challenge of ESBL. In our settings screening for ESBL production among bacteria isolates is not routinely done in many clinical laboratories and the evidence of treatment failure of most antibiotics is not well documented. Thus, the detection of ESBLs indicates the need for the use of appropriate antibacterial agents. ESBL detection has become a diagnostic challenge in clinical laboratories. In most cases, the standard disk diffusion tests are effective, and they are still recommended for ESBL detection in routine laboratories (Giriyapur et al., 2011).

There are limited data from surveillance studies on antimicrobial resistance in northern Tanzania. To the best of our knowledge this is the first report from the region with an exclusive focus on investigating the prevalence and antimicrobial resistant pattern of ESBL producing isolates. Therefore, our study presents the baseline information on the ESBL prevalence and resistance to antimicrobial agents and its association with clinical outcome. This present study suggests that clinical microbiology laboratories should take into account the diagnosis of ESBL 
producers in order to define the degree of the problem so as to establish a proper patient management and treatment protocol. We recommend more studies to investigate the magnitude of ESBL production in bacteria isolated from food of animal origins so that to have a comparison and envisage antibiotic usage in animal and human.

\section{Competing interests}

The authors declare that they have no competing interests.

\section{Authors' contribution}

$\mathrm{DK}, \mathrm{PN}, \mathrm{JC}$, and $\mathrm{BN}$ were involved in the conception and study design as well as data analysis. Microbiological analyses were done by NK, CM, FK and BK. VM and RK drafted the manuscript. All authors read and approved the final version of the manuscript.

\section{Acknowledgements}

We are grateful for excellent help from KCMC hospital. This work was supported by the HRSA Award T84HA21123, through Medical Education Partnership Initiative Mentored Training Research Programme at Kilimanjaro Christian Medical University College.

\section{Reference}

Babini, G.S. \& Livermore, D.M. (2000) Antimicrobial resistance amongst Klebsiella spp. collected from intensive care units in Southern and Western Europe in 1997-1998. Journal of Antimicrobial Chemotherapy 45, 183-189.

Bellíssimo-Rodrigues, F., Gomes, A.C.F., Passos, A.D.C., Achcar, J.A., Perdona, G.D.S.C. \& Martinez, R. (2006) Clinical outcome and risk factors related to extended-spectrum beta-lactamase-producing Klebsiella spp. infection among hospitalized patients. Memorias do Instituto Oswaldo Cruz 101, 415-421.

Chander, A. \& Shrestha, C.D. (2013) Prevalence of extended spectrum beta lactamase producing Escherichia coli and Klebsiella pneumoniae urinary isolates in a tertiary care hospital in Kathmandu, Nepal. BMC Research Notes 6: 487.

CLSI (2011) Performance standards for antimicrobial susceptibility testing; 20th informational supplement. CLSI document M100-S20. Clinical and Laboratory Standards Institute, Wayne, PA.

Collee, J.G., Miles, R.S. \& Watt, B. (1996) Tests for identification of bacteria. In Mackie and McCartney: Practical Medical Microbiology $14^{\text {th }}$ edition. Churchill Livingstone 131-149pp.

Food Insight (2012) Questions and Answers: Animal Antibiotics, Antimicrobial Resistance and Impact on Food Safety - See more at: http://www.foodinsight.org.

Giriyapur, R.S., Nandihal, N.W., Krishna, B.V.S., Patil, A.B. \& Chandrasekhar, M.R. (2011)Comparison of disc diffusion methods for the detection of Extended-Spectrum Beta Lactamase-Producing Enterobacteriaceae. Journal of Laboratory Physicians 3, 33-36.

Jacoby, G.A. \& Sutton, L. (1991) Properties of plasmids responsible for production of extendedspectrum $\beta$-lactamases. Antimicrobial Agents and Chemotherapy. 35. p.pp. 164-169.

Kariuki, S., Revathi, G., Corkill, J., Kiiru, J., Mwituria, J., Mirza, N. \& Hart, C.A. (2007) Escherichia coli from community-acquired urinary tract infections resistant to fluoroquinolones and extended-spectrum beta-lactams. Journal of Infection in Developing Countries. 1: 257262. 
Mshana, S.E., Imirzalioglu, C., Hain, T., Domann, E., Lyamuya, E.F. \& Chakraborty, T. (2011) Multiple ST clonal complexes, with a predominance of ST131, of Escherichia coli harbouring blaCTX-M-15 in a tertiary hospital in Tanzania. Clinical Microbiology and Infection 17, 1279-1282.

Mshana, S.E., Kamugisha, E., Mirambo, M., Chakraborty, T. \& Lyamuya, E.F. (2009) Prevalence of multiresistant gram-negative organisms in a tertiary hospital in Mwanza, Tanzania. BMC Research Notes 2:49.

Mshana, S.E., Hain, T., Domann, E., Lyamuya, E.F., Chakraborty, T. \& Imirzalioglu, C. (2013) Predominance of Klebsiella pneumoniae ST14 carrying CTX-M-15 causing neonatal sepsis in Tanzania. BMC Infectious Disease 13:466.

Mshana, S., Matee, M. \& Rweyemamu, M. (2013) Antimicrobial resistance in human and animal pathogens in Zambia, Democratic Republic of Congo, Mozambique and Tanzania: an urgent need of a sustainable surveillance system. Annals of Clinical Microbiology and Antimicrobials 12:28.

Ndugulile, F., Jureen, R., Harthug, S., Urassa, W. \& Langeland, N. (2005) Extended spectrum beta-lactamases among Gram-negative bacteria of nosocomial origin from an intensive care unit of a tertiary health facility in Tanzania. BMC Infectious Diseases 5: 86.

Paterson, D.L. (2000) Recommendation for treatment of severe infections caused by Enterobacteriaceae producing extended-spectrum beta-lactamases (ESBLs). Clinical Microbiology and Infection 6: 460-463.

Paterson, D.L. \& Bonomo, R.A. (2005) Extended-spectrum beta-lactamases: a clinical update. Clinical Microbiology Reviews 18, 657-686.

Paterson, D.L., Mulazimoglu, L., Casellas, J.M., Ko, W.C., Goossens, H., Von Gottberg, A., Mohapatra, S., Trenholme, G.M., Klugman, K.P., McCormack, J.G. \& Yu, V.L. (2000) Epidemiology of ciprofloxacin resistance and its relationship to extended-spectrum beta-lactamase production in Klebsiella pneumoniae isolates causing bacteremia. Clinical Infectious Diseases 30, 473-478.

Paterson DL, Ko WC, Von Gottberg A, Casellas JM, Mulazimoglu L, Klugman KP, et al. Outcome of cephalosporin treatment for serious infections due to apparently susceptible organisms producing extended-spectrum beta-lactamases: Implications for the clinical microbiology laboratory. J Clin Microbiol. 2001;39:2206-12.

Ramphal, R. \& Ambrose, P.G. (2006) Extended-spectrum beta-lactamases and clinical outcomes: current data. Clinical Infectious Disease 42, S164-S172.

Rawat, D. \& Nair, D. (2010) Extended-spectrum $\beta$-lactamases in Gram Negative Bacteria. Journal of Global Infectious Diseases 2, 263-274.

Rupp, M.E. \& Fey, P.D. (2003) Extended spectrum beta-lactamase (ESBL)-producing Enterobacteriaceae: considerations for diagnosis, prevention and drug treatment. Drugs $63,353-365$.

Spanu, T., Luzzaro, F., Perilli, M., Amicosante, G., Toniolo, a \& Fadda, G. (2002). Occurrence of Extended-Spectrum b-Lactamases in members of the family Enterobacteriaceae in ItalyImplications for resistance to b-lactams and other antimicrobial drugs. Antimicrobial Agents and Chemotherapy 46, 196-202.

Tsering, D.C., Das, S., Adhiakari, L., Pal, R. \& Singh, T.S. (2009) Extended Spectrum Betalactamase Detection in Gram-negative Bacilli of Nosocomial Origin. Journal of Global Infectious Diseases 1, 87-92.

Umadevi, S., Kandhakumari, G., Joseph, N.M., Kumar, S., Easow, J.M., Stephen, S. \& Singh, U.K. (2011). Prevalence and antimicrobial susceptibility pattern of ESBL producing gram negative bacilli. Journal of Clinical and Diagnostic Research 5, 236-239. 